$\mathrm{D}(-)$-Lactic acidosis may be more common than is thought and perhaps should be looked for in cases of metabolic acidosis in which the identity of the acid is not apparent.

I thank Professor J S Cameron, Dr C S Ogg, and Dr D G Williams for permission to report this case and Dr Pat Toseland for measuring the $\mathrm{D}(-)$-lactate concentrations.

1 Stolberg L, Rolfe R, Gitlin N, et al. D-Lactic acidosis due to abnormal gut flora. $N$ Engl f Med 1982;306:1344-8.

2 Oh MS, Phelps KR, Traube M, Barbosa-Saldivar JL, Boxhill C, Carroll HJ. D-Lactic acidosis in a man with short-bowel syndrome. $N$ Engl f Med 1979;301:249-52.

3 Carr DB, Shih VE, Richter JM, Martin JB. D-Lactic acidosis simulating a hypothalamic syndrome after bowel bypass. Ann Neurol 1982;11:195-7.

4 Thurn JR, Pierport GL, Ludrigsen CW. D-Lactic acidosis [Abstract]. Clin Res 1983;31:398.

5 Schoorel EP, Giesberts MAH, Blom W, VenGelderen HH. D-Lactic acidosis in a boy with short bowel syndrome. Arch Dis Child 1980;55:810-2.

(Accepled 17 Tanuary 1986

Department of Renal Medicine, Guy's Hospital, London SE1 9RT

PD MASON, MRCP, Wellcome research fellow

Correspondence to: Department of Medicine, Royal Postgraduate Medical School, Hammersmith Hospital, London W12 0HS

\section{Diurnal variation in onset of acute closed angle glaucoma}

Acute glaucoma results from closure of the angle in the anterior chamber of the eye by apposition of peripheral iris to cornea, which prevents the outflow of aqueous humour from the anterior segment; with continuing production of aqueous humour the intraocular pressure rises precipitously, producing the characteristic symptoms and signs of closed angle glaucoma-namely, decreased visual acuity, haloes around lights, and pain, which is often severe. 'Diurnal variation of intraocular pressure is well recognised ${ }^{2}$; we attempted to determine whether the onset of acute closed angle glaucoma varies on a similar diurnal cycle.

\section{Patients, methods, and results}

One hundred consecutive patients (mean age $66 \cdot 3$ (SD 10.1) years) presenting with acute closed angle glaucoma referred to this glaucoma unit during the eight years to 20 December 1983 were analysed retrospectively. Each patient was questioned individually, by a single observer, to determine the time of day (to the nearest hour) when symptoms of acute glaucoma became apparent; as angle closure produces rapidly progressive, severe effects the onset of symptoms is a reasonable approximation to the start of the acute attack. Details were verified from patients' records. Acute closed angle glaucoma was significantly more prevalent among women than men $\left(71\right.$ women $v 29$ men; $\chi^{2}=17.64, \mathrm{df}=1$, $\mathrm{p}<0.001$ )

The table shows the diurnal variation in the time of onset of acute closed angle glaucoma, with a peak incidence during the evening and a trough in the morning.

Hourly distribution of onset of acute closed angle glaucoma over eight years

\begin{tabular}{cccc}
\hline Time & No of patients & Time & No of patients \\
\hline 0100 & 2 & 1300 & \\
0200 & 6 & 1400 & \\
0300 & 1 & 1500 & 2 \\
0400 & 2 & 1600 & 6 \\
0500 & & 1700 & 6 \\
0600 & 2 & 1800 & 11 \\
0700 & 8 & 1900 & 13 \\
0800 & 4 & 2000 & 13 \\
0900 & 2 & 2100 & 6 \\
1000 & 2 & 2200 & 6 \\
1100 & 1 & 2300 & 3 \\
1200 & 1 & 2400 & 5 \\
\hline
\end{tabular}

Comparison of the 12 hour periods 0400 to 1500 and 1600 to 0300 yielded a significant difference $\left(\chi^{2}=31 \cdot 36, \mathrm{df}=1, \mathrm{p}<0.001\right)$. The hypothesis of a constant incidence throughout the day was not reasonable $\left(\chi^{2}=86.24, \mathrm{df}=23, \mathrm{p}<0.001\right)$, but when the logarithms of the observed counts were submitted to regression on a sine (hour) and cosine (hour) scale jointly on a 24 hour cycle assuming Poisson type errors, the regression was highly significant $\left(\chi^{2}=35 \cdot 83, \mathrm{df}=2, \mathrm{p}<0.001\right)$.

\section{Comment}

The depth of the anterior chamber of the eye is a dynamic variable that may change rapidly and transiently. ${ }^{3}$ Diurnal shallowing of the anterior segment has been shown; the depth and volume of the anterior chamber are significantly lower in the evening than the morning, and the anterior chamber angle decreases by $21 \%{ }^{+}$This obviously facilitates the onset of angle closure; individual differences in diurnal shallowing of the anterior chamber may explain why certain eyes progress to overt angle closure though other, apparently similar, eyes do not.

Closed angle glaucoma is a medical emergency; during a typical episode intraocular pressure may be above $50 \mathrm{~mm} \mathrm{Hg}$ (normal $10-20 \mathrm{~mm} \mathrm{Hg}$ ), producing irreversible ischaemic ocular damage within a few hours. This is the first significant evidence to confirm the hypothesis that acute glaucoma occurs mainly during the evening, with the following implications. Delay in management overnight may result in considerable impairment of sight; effectively, closed angle glaucoma is a form of blindness that may be prevented but only if management is started at an early stage. The onset of closed angle glaucoma is not easily recognised, but suspicious features include pain or decreased visual acuity with a fairly acute onset during the evening. A history of similar self limited episodes occurring at the same time of day, suggesting intermittent partial angle closure, would reinforce the diagnosis. Immediate ophthalmic treatment serves only to arrest the rapidly progressing ocular damage; of greater importance is early recognition by the general practitioner and immediate referral.

We thank Mr C West, University of Liverpool, for statistical advice, and Dr R Vogel, Merck Sharp and Dohme Ltd, for computer facilities. CVC is in receipt of the R D Lawrence research fellowship from the British Diabetic Association.

1 Kolker AE, Hetherington J. Becker-Shaffer's diagnosis and therapy of the glaucomas. 5 th ed. St Louis: C V Mosby, 1983:191.

2 Miller SJH. Parson's diseases of the eye. 17th ed. Edinburgh: Churchill Livingstone, 1984:191.

3 Mapstone R. Closed-angle glaucoma in eyes with non-shallow anterior chambers. Trans Ophthalmol Soc UK 1981;101:218-20

4 Mapstone R, Clark CV. Diurnal variation in the dimensions of the anterior chamber. Arch Ophthalmol 1985;103:1485-6.

Accepted 13 February 1986)

Glaucoma Unit, St Paul's Eye Hospital, Liverpool L3 9PF

CHARLES V CLARK, MD, FRCSED, research fellow

ROY MAPSTONE, MD, FRCS, consultant ophthalmic surgeon

Correspondence to: Dr C V Clark, Department of Ophthalmology, University of Edinburgh, Princess Alexandra Eye Pavilion, Edinburgh EH3 9HA.

\section{Source of infection in candida endophthalmitis in drug addicts}

Heroin addiction is currently a major medical and social problem in Great Britain. An epidemic of presumed candidal endophthalmitis, a recognised complication of heroin abuse, was recently reported from Glasgow. ${ }^{1}$ In this series an appreciable temporospatial clustering of patients was observed, suggesting a common source of infection. We report the results of our attempts to ascertain the possible origins of the infection in addicts.

\section{Patients, methods, and results}

Twenty three heroin addicts were diagnosed as having candidal endophthalmitis between November 1982 and August 1985. The diagnostic criteria have been described.

Analysis of drug diluent-The diluent used by 22 addicts was lemon juice from plastic lemons. Five patients submitted their current lemon for analysis; the caps and juices were cultured for fungal contamination. Two lemons yielded pure, heavy growths of Candida albicans. Two lemons were nearly full, indicating that they had been bought recently, and one was completely empty; these three lemons yielded negative results on culture. As a control seven plastic lemons bought six to 12 months previously were obtained from friends and colleagues only one produced a growth of a non-pathogenic yeast. Of 15 lemons bought at random from corner shops in the area where the addicts lived, 11 were within their "best by" dates and yielded negative results on culture; Aspergillus niger was cultured from the juice of one of the four lemons past their "best by" dates.

Fungicidal effect of lemon juice-Sulphur dioxide is the preservative used in the plastic lemons. Juice from new lemons was inoculated with $C$ albicans and incubated for 48 hours; no growth was seen. The juice from new lemons that had been steamed for 10 minutes to drive off the preservative did not inhibit growth of candida. 
Contamination of paraphernalia used for injection-Four addicts submitted their injection paraphernalia for culture. $C$ albicans was isolated from one set and $C$ parapsilosis from another. The remaining two sets yielded negative results.

Recovery of fungi from street heroin-It is illegal to obtain heroin sold in the streets. Legal restrictions on the availability of confiscated drugs precluded analysis, despite our attempts to arrange this.

Effect of diacetylmorphine hydrochloride on growth of $C$ albicans-Previous studies failed to isolate Candida spp from heroin sold in the street. ${ }^{23}$ Cultures of $C$ albicans in the exponentially growing and resting phases were found to be inhibited by diacetylmorphine in agar diffusion susceptibility tests. Excision of the inhibition zones and further incubation in drug free medium did not enhance growth of the organisms. This indicates a fungicidal potential for the drug. The minimum inhibitory concentration using agar and broth dilution methods was $25-30 \mathrm{~g} / 1$.

\section{Comment}

It has been suggested that juice from fresh lemons may provide a reservoir for candidal infection. ${ }^{+5}$ To our knowledge, however, plastic lemons have not previously been incriminated. This study suggests that the juice in plastic lemons from which the preservative, sulphur dioxide, has evaporated can become contaminated with $C$ albicans, probably from the addict's flora. Although legal restrictions precluded us from analysing heroin sold in the street for fungal contamination, the fact that diacetylmorphine was found to be fungicidal for $C$ albicans suggests that the heroin itself was a less likely source of infection. Fungal endophthalmitis is a blinding disease and is one manifestation of the multifocal candidal disease that has recently been reported in heroin addicts. ${ }^{2}$ We maintain that this additional risk of heroin addiction should be made more widely known as a disincentive to tentative abusers of heroin.

We thank the clinicians of the Glasgow eye departments for making available specimens from their cases and the technical staff of the medical mycology unit for their help.

1 Servant JB, Dutton GN, Ong-tone L, Barrie T, Davey C. Candidal endophthalmitis in Glaswegian heroin addicts: report of an epidemic. Trans Ophthalmol Soc UK 1985;104:297-308.

2 Mellinger M, DeBeauchamp O, Gallien C, Ingold R, Taboada MJ. Epidemiological and clinical approaches to the study of candidiasis caused by Candida albicans in heroin addicts in the Paris region: analysis of 35 observations. Bull Narc 1982;34:61-81.

3 Tuazon CU, Hill R, Sheagren JN. Microbiologic study of street heroin and injection paraphernalia. I Infect Dis 1974;129:327-9.

4 Hoy J, Speed B. Candidiasis in heroin users. Br Med f 1983;287:1549. heroin abusers. Med I A ust 1983;140:780-1.

Accepted 17 February 1986

Medical Mycology Unit, Department of Dermatology, University of Glasgow, Glasgow G11 6NU

G S SHANKLAND, BSC, research assistant

M D RICHARDSON, BSC, PHD, principal mycologist

Tennent Institute of Ophthalmology, University of Glasgow, Glasgow G11 6NU

G N DUTTON, MD, FRCS, senior lecturer

Correspondence to: Mrs Shankland.

\section{Autoamputation of infant's finger by knitted mitten: a forgotten hazard}

It is nearly 20 years since the British Medical Association drew attention to the danger to infants' fingers posed by mittens knitted from synthetic materials. ${ }^{1}$ The case described below is thus a timely reminder.

\section{Case report}

A 5 week old girl was put to sleep in knitted mittens by her parents. Overnight the infant was fretful, but the parents did not realise why. In the morning they could not remove the left mitten and so took her to their general practitioner. He carefully cut off the mitten to find the tip of the index finger swollen and black (figure).

Dry gangrene had been caused by the finger passing through the open knitting of the mitten and becoming stuck, so that the blood supply had been cut off. An expectant policy was adopted; the blackened finger tip was demarcated and separated, and the remaining stump healed satisfactorily with the loss of the terminal phalange.

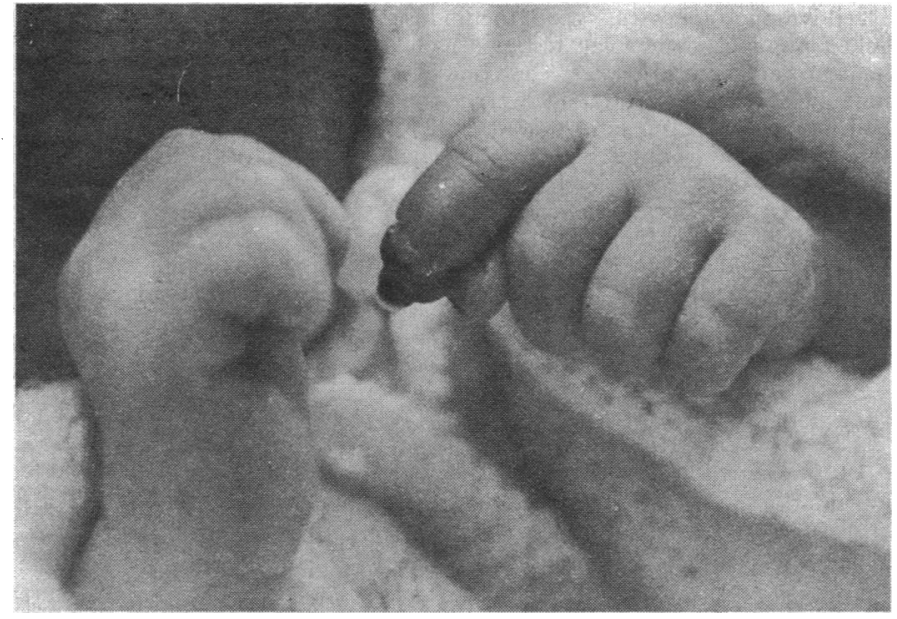

Swollen and black index finger.

\section{Comment}

The incidence of similar unfortunate episodes is unknown. Review of Hospital Activity Analysis data listed under "amputations" for the years 1975-84 shows that less than $1 \%$ of amputations occur among infants under 1 year of age; most occur in men aged over 20 and are probably due to accidents at work. The amputations listed are almost certainly surgical procedures, and cases such as that above are probably not included.

This case is important because it could have been prevented. Clothing for infants is often knitted, and is either produced by commercial manufacturers or home made. Ornamental knitting patterns with fairly large holes and the use of less yielding synthetic fibres increase the risk of digits becoming trapped between strands. It would be safest to use only tight woven rather than knitted material for infants under 1 year of age.

1 Noott GG. Hazards from nylon. Br Med f 1967:370

(Accepted 25 March 1986)

Department of Orthopaedics, Newham General Hospital, London E13 M G MATTHEWS, FRCS, orthopaedic registrar

\section{Erythroderma resembling Sézary syndrome after treatment with Fansidar and chloroquine}

There have been reports of serious ${ }^{1}$ and indeed fatal $^{2}$ multisystem illnesses after patients have received pyrimethamine and sulfadoxine (Fansidar) as malarial prophylaxis for Plasmodium falciparum resistant to chloroquine. We describe a patient who developed an illness resembling Sézary syndrome after treatment with chloroquine and Fansidar.

\section{Case report}

A previously well 45 year old entomologist with no history of allergy visited a northern province of Sumatra to conduct a mosquito survey in an area where chloroquine resistant falciparum malaria had been reported. He took chloroquine $150 \mathrm{mg}$ every third day (seven tablets in total) and Fansidar (sulfadoxine $500 \mathrm{mg}$ and pyrimethamine $25 \mathrm{mg}$ ) one tablet weekly (six tablets in total).

Three weeks after arrival he became unwell with fever, diarrhoea, and general malaise and was advised to take an extra two tablets of Fansidar. His condition deteriorated, and he arrived in Holland with fever, erythroderma, diarrhoea, and jaundice. There was generalised lymphadenopathy, hepatosplenomegaly with raised activities of hepatocellular enzymes, and eosinophilia with negative parasitology and viral studies. Treatment was started with prednisolone $40 \mathrm{mg}$ daily, and although the hepatitis improved his general condition remained poor.

On returning to England he was erythrodermic with generalised lymphadenopathy. There was an eosinophilia and a blood film showed abnormal lymphoid cells with features of Sézary cells. The following yielded normal results: blood count; measurement of erythrocyte sedimentation rate; Paul-Bunnell, Venereal Disease Research Laboratory, and Treponema pallidum haemagglutination tests; tests for hepatitis B surface antigen, hepatitis A antibodies, and human 